\title{
Synthesis, Characterization and Application of Al,Fe-Pillared Clays
}

\author{
P. Banković* , A. Milutinović-Nikolić, N. Jović-Jovičić, J. Dostanić, Ž. Čupić, \\ D. LONČAREVIĆ AND D. JovanOVIĆ \\ Institute of Chemistry, Technology and Metallurgy, University of Belgrade \\ Department of Catalysis and Chemical Engineering, Njegoševa 12, 11000 Belgrade, Serbia
}

\begin{abstract}
Al,Fe-pillared clay was synthesized from domestic clay from Bogovina according to a common procedure: grinding, sieving, Na exchange, pillaring, drying and calcination. Two synthesized samples differing only in calcining conditions were prepared. Phase composition and textural properties of the starting clay and synthesized pillared clays were characterized using X-ray diffraction and physisorption of nitrogen. Catalytic tests were performed using sample with better textural properties being the one submitted to milder calcining conditions. Catalytic wet peroxide oxidative degradation of aromatic compounds phenol and tartrazine on the synthesized catalyst was confirmed showing better efficiency in the case of tartrazine.
\end{abstract}

PACS numbers: 61.05.C-, 61.43.Gt, 61.46.-w, 68.43.-h, 82.65.+r

\section{Introduction}

Pillaring is a process of smectite modification used to obtain materials that have found a wide range of applications in catalytic, adsorption and separation processes. Common procedure for pillared clay (PILC) preparation is: swelling of smectite in water, exchange of the interlayer cations by partially hydrated polymeric or oligomeric metal cation complexes in the interlamellar region of the starting clay, drying and calcining of wet cake formed of expanded clay in order to have the metal polyoxocations transformed into metal oxide pillars [1].

One of the most promising solutions for the elimination of pollutants from waste waters is catalytic wet peroxide oxidation (CWPO) using pillared clays. It has been proven as a method extremely effective under mild conditions for the degradation of organic pollutants partially or completely transforming them to $\mathrm{CO}_{2}[2-4]$. Moreover, hydrogen peroxide is a desirable environment friendly oxidizing agent since it is nontoxic and does not form any harmful by-products.

The aim of the research presented in this work was to apply PILCs as catalysts in the CWPO of organic pollutants with goal of finding appropriate solutions for the environmental protection.

The efficiency of CWPO is highly influenced by the properties of applied PILC catalyst. PILC properties are affected by various synthesis parameters such as solidliquid ratio, clay origin, particle size, type of oligomeric

\footnotetext{
* corresponding author; e-mail: predragb@nanosys.ihtm.bg.ac.rs
}

metal cation or mixture of cations, intercalation conditions, temperature and duration of calcining etc. In this work the pillaring process was performed on $2 \mu \mathrm{m}$ fraction of Bogovina-originated smectite clay. PILC catalysts based on Al PILC with $\mathrm{Fe}^{3+}$ as active cation were synthesized where several synthesis parameters were maintained constant such as clay size and origin, type of pillaring cations and their ratio, cation/clay ratio etc. On the other hand, two extreme calcining sets of parameters found in literature $[5,6]$ were applied and their influence on the catalyst properties was investigated. Among the two obtained catalysts the one with better textural properties was tested in the CWPO degradation of phenol and food dye tartrazine (presented in Fig. 1).<smiles>[NH3+]OC(=O)c1nn(-c2ccc(S(=O)(=O)O[Na])cc2)c(O)c1/N=N/c1ccc(S(=O)(=O)O[Na])cc1</smiles>

Fig. 1. Structural formula of tartrazine.

\section{Experimental}

Starting material was domestic clay from Bogovina $[7,8]$. The $2 \mu \mathrm{m}$ fraction of this clay with cation exchange capacity (estimated by ammonium acetate method) of $765 \mathrm{mmol} \mathrm{kg}{ }^{-1}$ was used in further experiments and denoted as raw clay. After transforming the original dominantly $\mathrm{Ca}$ form of smectite into its corresponding $\mathrm{Na}$ 
form the process of pillaring was carried out according to a common procedure [9]. Pillaring solutions were adjusted to have the $\mathrm{Fe}^{3+} /\left(\mathrm{Al}^{3+}+\mathrm{Fe}^{3+}\right)$ atomic ratio of 10 and $\mathrm{OH}^{-} /\left(\mathrm{Al}^{3+}+\mathrm{Fe}^{3+}\right)=2.0$. The procedure included continuous stirring at $60^{\circ} \mathrm{C}$ for $3 \mathrm{~h}$ and at room temperature overnight. In the next step the appropriate amount of the pillaring solutions, required for the ratio - mmol $\left(\mathrm{Al}^{3+}+\mathrm{Fe}^{3+}\right) / \mathrm{g}$ clay - to be 20 , was slowly added into aqueous suspension of Na-exchanged smectite. After being rigorously stirred at $80^{\circ} \mathrm{C}$ for $3 \mathrm{~h}$ the final suspension was stirred at room temperature overnight, alternately centrifuged (5000 rpm) and washed with water, and finally air-dried overnight at $110^{\circ} \mathrm{C}$.

Two extreme time/temperature calcining regimes presented in Fig. 2 were tested in the synthesis of catalyst. The sample calcined at maximal temperature of $300^{\circ} \mathrm{C}$ for $2 \mathrm{~h}$ was referred to as AlFe10 PILC-1 and the one calcined at maximal temperature $500^{\circ} \mathrm{C}$ for $8 \mathrm{~h}$ as $\mathrm{AlFe} 10$ PILC-2.

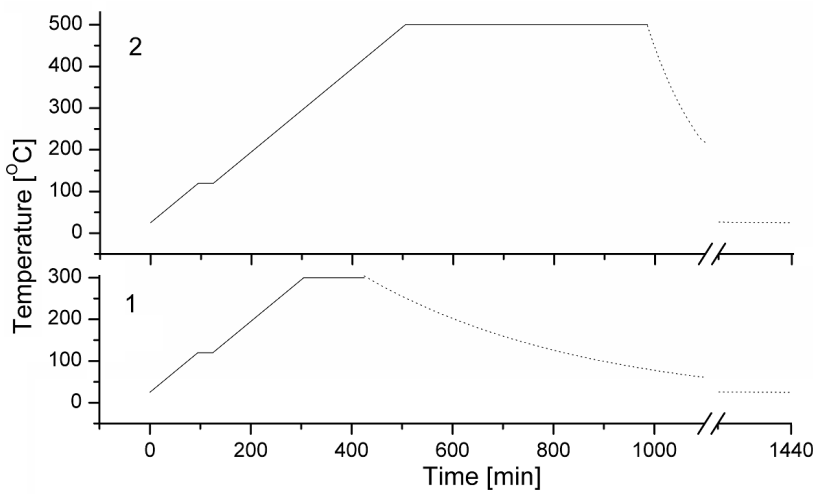

Fig. 2. Regime of calcination: (1) AlFe10 PILC-1 and (2) AlFe10 PILC-2.

X-ray diffraction (XRD) patterns for powders of raw and pillared clays were obtained using a Philips PW $1710 \mathrm{X}$-ray powder diffractometer with a $\mathrm{Cu}$ anode $(\lambda=$ $0.154178 \mathrm{~nm})$.

A Spectro Spectroflame M, iinductively coupled plasma optical emission spectrometer (ICP-OES), was used to determine potential leaching of pillaring cations from the catalysts.

Nitrogen adsorption-desorption isotherms were determined on Sorptomatic 1990 Thermo Finningen at $-196^{\circ} \mathrm{C}$. The samples were outgassed at $160^{\circ} \mathrm{C}$, during $20 \mathrm{~h}$. Various models and appropriate software-WinADP were used to analyze obtained isotherms. Specific surface area of the samples, $S_{\mathrm{BET}}$, was calculated according to the Brunauer-Emmett-Teller method [10, 11]. Total pore volume was calculated according to the Gurvitch method for $p / p_{0}=0.98[10,11]$. Pore size distribution for mesopores was calculated according to the BarrettJoyner-Halenda method from the desorption branch of isotherm [12]. Micropores were analyzed using DubininRadushkevich method [11, 13].
The reactions of pollutant oxidative degradation were carried out in the manner analogical to the procedure previously used for phenol degradation [14] and described below. Pyrex reactor thermostated at $310 \mathrm{~K}$ (Julabo MC 4 circular heater) and equipped with a stirrer was used. $100 \mathrm{ml}$ aqueous solutions of each pollutant (phenol and tartrazine) were stirred with $0.5 \mathrm{~g}$ of solid catalyst and the quantity of hydrogen peroxide was added that slightly exceeded stoichiometric quantity needed to totally transform each of them into $\mathrm{CO}_{2}$. Aliquots were taken at predetermined periods of time and, after filtration (Cole-Palmer nylon syringe filters with PP housing; pore size $=0.20 \mu \mathrm{m}$ ), analyzed by UV-Vis spectrophotometry. The spectra were obtained using Thermo Electron Nicolet Evolution 500 UV-Vis spectrophotometer. UV absorption peaks at $427 \mathrm{~nm}$ for the dye and $270 \mathrm{~nm}$ for phenol were chosen for monitoring the catalytic process.

\section{Results and discussion}

According to X-ray diffraction patterns (Fig. 3) the following phases were identified in the investigated samples: smectite, quartz, and feldspar [15].

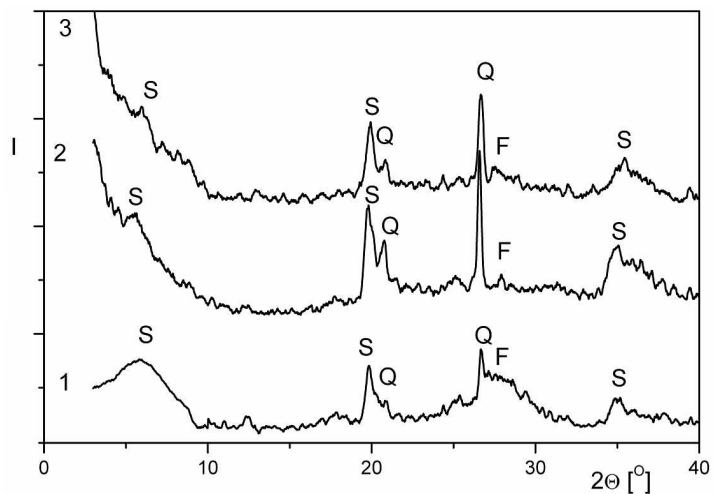

Fig. 3. X-ray diffraction patterns of (1) raw clay, (2) AlFe10 PILC-1 and (3) AlFe10 PILC-2 where $\mathrm{S}=$ smectite, $\mathrm{Q}=$ quartz and $\mathrm{F}=$ feldspar

A small hump between 19 and $30^{\circ} 2 \theta$ attributed to X-ray amorphous matter was also observed. The (001) smectite peak around $2 \theta=6^{\circ}$ shifts during the pillaring process. For the starting clay, which shows swelling properties, the (001) smectite peak occurred at $2 \theta=5.78^{\circ}$ corresponding to basal spacing of $1.53 \mathrm{~nm}$. After pillaring the peak shifted to $2 \theta=5.40^{\circ}\left(d_{001}=1.64 \mathrm{~nm}\right)$ and $2 \theta=5.52^{\circ}\left(d_{001}=1.60 \mathrm{~nm}\right)$ for AlFe10 PILC- 1 and AlFe10 PILC-2, respectively, and the basal spacing remained fixed. The obtained results are in accordance with previously published data [3, 6, 16-19].

Figure 4 shows nitrogen adsorption-desorption isotherms for the investigated samples.

The curves presented in Fig. 4 correspond to the type II isotherms according to IUPAC classification [11, 20]. A sharp decline in the region of low relative pressures 


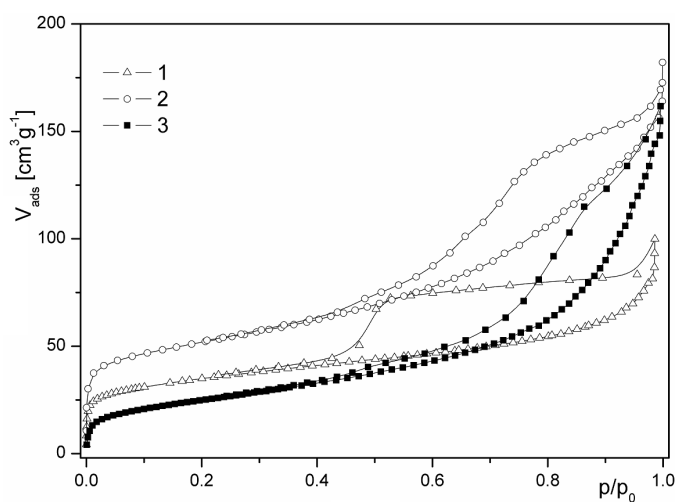

Fig. 4. Nitrogen adsorption-desorption isotherms registered for: (1) $2 \mu \mathrm{m}$ fraction of smectite clay, (2) AlFe10 PILC-1 and (3) AlFe10 PILC-2.

suggests the presence of micropores. All the isotherms have reversible part at low relative pressures and hysteresis loops at higher relative pressures corresponding to the H3 type of hysteresis cycle characteristic of aggregated plane particles forming slit shape pores $[10,11]$. Relevant data for the raw clay and both synthesized samples obtained using WinADP software are presented in Table.

TABLE

Selected textural properties of the investigated samples.

\begin{tabular}{c|c|c|c|c|c}
\hline \hline Sample & $\begin{array}{c}S_{\text {BET }} \\
{\left[\mathrm{m}^{2} / \mathrm{g}\right]}\end{array}$ & $\begin{array}{c}V_{0.98} \\
{\left[\mathrm{~cm}^{3} / \mathrm{g}\right]}\end{array}$ & $\begin{array}{c}V_{\text {mic }} \\
{\left[\mathrm{cm}^{3} / \mathrm{g}\right]}\end{array}$ & $\begin{array}{c}D_{\text {max }} \\
{[\mathrm{nm}]}\end{array}$ & $\begin{array}{c}D_{\text {med }} \\
{[\mathrm{nm}]}\end{array}$ \\
\hline Raw clay & 125 & 0.125 & 0.051 & 3.8 & 3.9 \\
AlFe10 PILC-1 & 172 & 0.229 & 0.072 & 5.3 & 7.3 \\
AlFe10 PILC-2 & 91 & 0.217 & 0.039 & 3.7 & 10.0 \\
\hline
\end{tabular}

$S_{\mathrm{BET}}$ - specific surface area; $V_{0.98}$ - total pore volume, $V_{\mathrm{mic}}$ - micropore volume, $D_{\max }$ - the pore diameter where the maximum of derivative cumulative volume curves is reached, $D_{\text {med }}$ - median value of pore diameter.

In all the samples pores from the mesopore region (pores with diameter within $2-50 \mathrm{~nm}$ range) prevail. Pore size distribution for mesopores is calculated according to the Barrett--Joyner-Halenda method and the pore diameter where the maximum of derivative cumulative volume curves is reached $\left(D_{\max }\right)$ and median value of pore diameter $\left(D_{\text {med }}\right)$ are also given in Table.

Table shows total pore volume for pillared samples comparing to the non-pillared one. As for the specific surface area and volume of micropores they increase for AlFe10 PILC-1 and decrease for AlFe10 PILC-2. Longer heat treatment at higher temperature $\left(500^{\circ} \mathrm{C}\right.$ and $8 \mathrm{~h}$, see Fig. 2) applied to AlFe10 PILC-2 resulted in gradual pore blocking that dominantly occurs in pores with smaller diameter reducing micropore volume probably due to temperature induced increase in solid state diffusion. From
$D_{\max }$ and $D_{\text {med }}$ values it can be concluded that the pillaring process leads to the shift of mesopore fractions toward greater mesopore diameters. On the other hand, in AlFe10 PILC-1 expected increase in the micropore volume in comparison with raw clay was achieved.

Therefore, after the synthesis and characterization only AlFe10 PILC-1 which had better textural properties was tested in the CWPO of phenol and tartrazine under above defined conditions.

For the comparison purposes the adsorption of both pollutants on AlFe10 PILC-1 was investigated under conditions equal to those applied in the CWPO reactions but without addition of hydrogen peroxide. Comparative presentation of catalytic degradation and adsorption is given in Fig. 5 for phenol and in Fig. 6 for tartrazine.

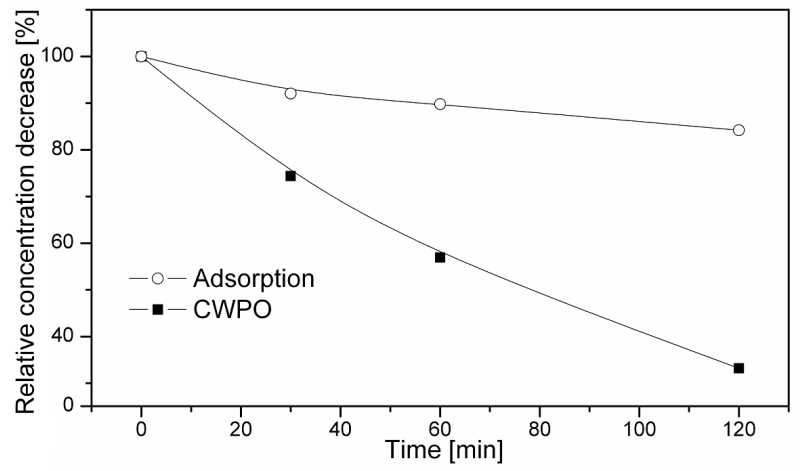

Fig. 5. Relative change in the concentration of phenol during adsorption and CWPO reaction.

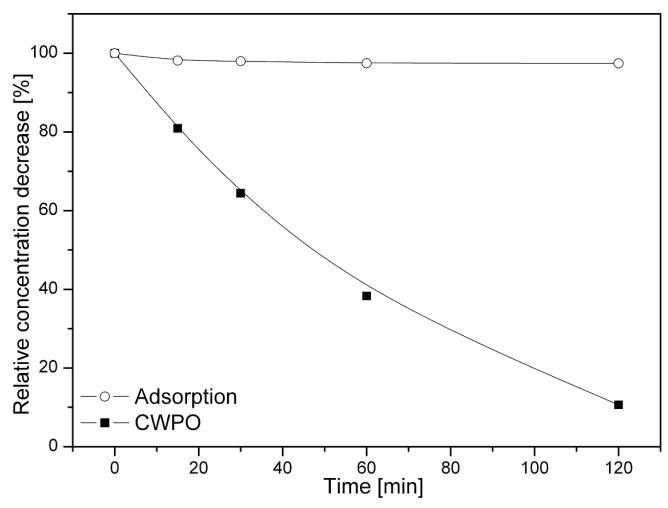

Fig. 6. Relative change in the concentration of tartrazine during adsorption and CWPO reaction.

It was shown that after $2 \mathrm{~h}$ the amount of pollutants removed from the system by adsorption was significantly smaller than by catalytic degradation for both pollutants.

The presented data show that the synthesized catalyst is applicable in wet hydrogen peroxide oxidation of the aromatic compounds used in this research. For the investigated AlFe10 PILC-1 catalyst- $\mathrm{H}_{2} \mathrm{O}_{2}$ - pollutant system higher degradation level was observed for tartrazine, 
while the degradation was not as effective in the case of phenol.

In order to test the chemical stability of the synthesized catalyst in the investigated system the presence of inorganic cations in the reaction mixture was analyzed. The obtained optical emission spectra confirmed that the $\mathrm{Al}^{3+}$ and $\mathrm{Fe}^{3+}$ ion concentrations in the filtrates taken after $24 \mathrm{~h}$ of the reaction did not exceed $0.01 \mathrm{ppm}$. These results show that leaching is negligible confirming that the pillaring cations are well incorporated in the pillar structure.

For better quantification of the obtained experimental results a comparison with data previously published elsewhere is given.

There are numerous works dedicated to the CWPO of phenol $[3,14,16,21,22]$, while it was not the case for the CWPO of tartrazine. In most of the published papers dealing with CWPO of phenol it was shown that after $1 \mathrm{~h}$ of the reaction phenol degradation was similar or lower than the one obtained in this research, but after $2 \mathrm{~h}$ often exceeded the degradation efficiency of our system. This is probably due to the fact that in all mentioned papers the reaction conditions were adjusted to $\mathrm{pH}$ of about 3.7 , the value that provides maximum oxidation rate [22] and/or higher temperatures. In our case, $\mathrm{pH}$ was not adjusted and the process optimization was not carried out.

As for tartrazine literature review has not provided relevant data on its degradation using CWPO, but there are those for the Fenton process [23]. Unlike the method employed in our work, the Fenton process is a homogeneous catalytic process and direct comparison of the results is not possible. Range of phenol degradation after $1 \mathrm{~h}$ of the reaction, reported in the work [23] was 40-98\% depending on the amount of hydrogen peroxide and $\mathrm{Fe}^{2+}$ ions introduced into the reaction system. In here investigated CWPO reaction the corresponding degradation was $62 \%$ although the amount of used peroxide was 40 500 times smaller. After $2 \mathrm{~h}$ of the reaction we found the elimination of the dye to be about $90 \%$. Finally, the advantages of the CWPO applied in this work over the Fenton process are: the solid PILC catalyst is easily removable from the system, hence does not represent any threat to the environment, the catalyst is stable as it was shown in the ICP-OES tests, and it might be reused.

\section{Conclusion}

Successful pillaring of smectite clay from Bogovina (Serbia) with $\mathrm{Al}^{3+}$ and $\mathrm{Fe}^{3+}$ cations was performed and confirmed by X-ray diffraction and nitrogen physisorption test. Increased temperature and prolonged calcination time were shown to cause derogation of textural properties of the synthesized pillared clay, particularly specific surface area and micropore volume. The sample with better textural properties was chosen for catalytic wet peroxide oxidation tests. It was efficient in the oxidative degradation of investigated aromatic compounds: phenol and tartrazine. It was also shown that the amount of pollutants removed from the system by adsorption was significantly smaller than by catalytic degradation for both pollutants being negligible for tartrazine. Higher catalytic degradation level was observed for tartrazine than for phenol.

The principal goal of this work to confirm the possibility of use of domestic clay in the synthesis of pillared clay catalyst for the degradation of different organic water pollutants was fulfilled.

\section{Acknowledgments}

This work was supported by the Ministry of Science and Technological Development of the Republic of Serbia (projects 166001B and 142019B).

\section{References}

[1] H.J. Chae, I.-S. Nam, S.W. Ham, S.B. Hong, Catal. Today 68, 31 (2001).

[2] S.-C. Kim, D.-K. Lee, Catal. Today 97, 153 (2004).

[3] E. Guélou, J. Barrault, J. Fournier, J.M. Tatibouët, Appl. Catal. B 44, 1 (2003).

[4] S. Caudo, G. Centia, C. Genovesea, S. Perathoner, Appl. Catal. B 70, 437 (2007).

[5] A.S. Reis Jr., J.D. Ardisson, Clays Clay Miner. 51, 33 (2003).

[6] P. Cañizares, J.L. Valverde, M.R. Sun Kou, C.B. Molina, Microporous Mesoporous Mater. 29, 267 (1999).

[7] Z. Vuković, A. Milutinović-Nikolić, J. Krstić, A. Abu-Rabi, T. Novaković, D. Jovanović, Mater. Sci. Forum 494, 339 (2005).

[8] Z. Vuković, A. Milutinović-Nikolić, Lj. Rožić, A. Rosić, Z. Nedić, D. Jovanović, Clays Clay Miner. 54, 697 (2006).

[9] V. Kaloidas, C.A. Koufopanos, N.H. Gangas, N.G. Papayannakos, Microporous Mater. 5, 97 (1995).

[10] S.H. Gregg, K.S. Sing, Adsorption, Surface Area and Porosity, Academic Press, New York 1967.

[11] F. Rouquerol, J. Rouquerol, K. Sing, Adsorption by Powders and Porous Solids, Academic Press, London 1999.

[12] P.A. Webb, C. Orr, Analytical Methods in Fine Particle Technology, Micrometrics Instrument Corporation, Norcross (USA) 1997.

[13] M.M. Dubinin, Progress in Surface and Membrane Science, Academic Press, New York 1975.

[14] J. Barrault, J.-M. Tatibouët, N. Papayannakos, Comptes Rend. Acad. Sci., Ser. IIC, Chem. 3, 777 (2000).

[15] International Center for Diffraction Data - Joint Committee on Powder Diffraction Standards, Powder Diffraction Data, Swarthmore (PA) 1990.

[16] J.G. Carriazo, M.A. Centeno, J.A. Odriozola, S. Moreno, R. Molina, Appl. Catal. A 317, 120 (2007).

[17] S. Azabou, W. Najjar, A. Gargoubi, A. Ghorbel, S. Sayadi, Appl. Catal. B 77, 166 (2007). 
[18] W. Najjar, S. Azabou, S. Sayadi, A. Ghorbel, Appl. Catal. B 74, 11 (2007).

[19] P. Yuan, F. Annabi-Bergaya, Q. Tao, M. Fan, Z. Liu, J. Zhu, H. He, T. Chen, J. Colloid Interface Sci. 324, 142 (2008).

[20] K.S.W. Sing, D.H. Everett, R.A.W. Haul, L. Moscou, R.A. Pierotti, J. Rouquerol, T. Siemieniewska, Pure Appl. Chem. 57, 603 (1985).
[21] J. Barrault, M. Abdellaoui, C. Bouchoule, A. Majesté, J.M. Tatibouët, A. Louloudi, N. Papayannakos, N.H. Gangas, Appl. Catal. B 27, L225 (2000).

[22] N. Sanabriaa, A. Álvareza, R. Molinaa, S. Moreno, Catal. Today 133-135, 530 (2008).

[23] M.A. Behnajady, N. Modirshahla, F. Ghanbary, J. Hazard. Mater. 148, 98 (2007). 